\title{
ITS THE EXPERIENCE, NOT THE PRICE
}

\author{
Lee Green \\ Director \\ IBM Corporate Identity \& Design \\ Somers, NY U.S.A.
}

IBM has a long history of focusing on design and usability as a core competency and key differentiator for its branded products. From wearable and hand-held devices to super computers, design plays a key role in the development of advanced technology solutions. IBM has also utilized design for years to work in conjunction with IBM Research on advanced prototypes of the future. Some, like Blue Gene L, are now being developed for Lawrence Livermore Labs; others, such as our electronic newspaper concepts, or voice and video recognition headsets, are visions of the future and demonstrations of emerging IBM innovation.

In the last several years, IBM Corporate Design has teamed with IBM Engineering and Technology Services (E\&TS) to extend Design Services as part of IBM's offering to customers. ${ }^{2}$ Recently they have also begun to extend these services in conjunction with IBM Business Consulting Services. We are engaging with IBM clients around the world to provide our expertise in product design, human factors, and engineering. We are also now offering design consulting services to help IBM clients consider how they can envision and extend new experiences to their customers and leverage design to differentiate their offerings from their competition. This is a new offering being extended to IBM clients that no other IT company provides.

Design Services works with clients to understand marketplace context, create new user scenarios, model these scenarios, validate them and then implement solutions. Often this involves observation research to uncover new technology and service opportunities.

We have designed medical solutions for the Mayo Clinic, wireless floor trader solutions for the New York Stock Exchange, ${ }^{3}$ and have many other projects in develop-

${ }^{1}$ Copyright $(C 2005$, Lee Green. Used with permission.

${ }^{2} \mathrm{Http}: / / \mathrm{www}-03 . \mathrm{ibm} . c 0 m /$ technology/designconsulting/index.html.

${ }^{3}$ See http://www-03.ibm.com/technology/designconsulting/cs_nyse.html. 
ment. ${ }^{4}$ These include consumer electronics, medical monitoring concepts, and home entertainment concepts. We are also supporting IBM's engagement with Culturecom in China and their eTown initiative to extend network computing access throughout rural cities in China. This information access will provide educational information and support local economic growth. The first of these eTowns was jointly announced July 15, 2004 in Yun An, Guang Dong province.

\section{ABOUT THE AUTHOR}

Lee Green is the WW Director of Corporate Identity and Design for IBM Corporation. He has responsibility for IBM's worldwide product industrial design, advanced technology design, brand experience initiatives, and IBM's recently launched Design Services offering for IBM clients. Mr. Green has played a pivotal role in IBM's re-branding efforts over the last 12 years, which have included the redesign of all IBM products. He also leads the corporation's efforts in the area of "advanced concept design."

In his 25-year career with IBM he has held numerous design and management positions. Recently, he has launched IBM's Design Services working in conjunction with IBM's Engineering and Technology Group and with IBM Business Consulting Services. This capability provides Design Services Consulting as an IBM offering to customers. In addition to industrial design and human factors, it provides Design Consulting services to help IBM customers consider how they can extend new experiences to their customers, utilize design to differentiate their offerings from their competition, and leverage innovative IBM technology to enable these solutions.

Mr. Green has an undergraduate degree in design from Temple University and a Master's degree in communications design from Rochester Institute of Technology. He has published numerous articles and case studies on a variety of design and identity topics. He has also taught design courses and lectured on design at Stanford University, Harvard, MIT, and RIT, and was recently named Rochester Institute of Technology 2004 Distinguished Alumni of the Year. He currently serves on the Board of Directors and Advisory Board for the Design Management Institute.

${ }^{4}$ For an example, see http://www-03.ibm.com/technology/designconsulting/cs_orange.html. 